\title{
DOCUMENTS
}

\section{CONCEPT OF MONGOLIA'S FOREIGN POLICY}

The Cold War which dominated international relations since the end of World War II has come to an end, the mutually opposing bipolar world structure has collapsed, and a process of forming a new international order is gaining momentum.

In line with trends of advancing human society, in particular with requirements of economic and technological progress, the nations of the world are drawing closer together, and conditions for enhancing their relationship are taking shape.

The disintegration of the world socialist system and the Soviet Union has dramatically changed the external situation of Mongolia which used to be aligned with them. The major changes taking place in Mongolia's two neighboring countries have a direct impact on its external environment.

The restructuring and reforming of the country's political, social and economic systems provide it with favorable conditions for conducting a foreign policy based on realism and according priority to its national interests.

Based on these external and internal factors, the concept of Mongolia's foreign policy is defined as follows.

\section{GENERAL PROVISIONS}

1. Independent and sovereign Mongolia, in terms of its state structure, is unitary State upholding rights, freedoms, and a free economy, in political and geographical respects; it is a developing country in Asia, landlocked between two great powers. Mongolia's foreign policy shall be based on its national interests, as defined in its Constitution: the country's specific external and internal situation constitutes the basis for determining its foreign policy objectives, principles and priorities

2. Mongolia's foreign policy objectives reside in ensuring its independence and sovereignty by following the trends of human Society's advancement, maintaining friendly relations with all coun-tries, strengthening its position in the international community and forming with influential countries in the region and in the world a network of relationships based on the interdependence of po-litical, economic and other interests. 
3. Mongolia shall pursue an open and non-aligned policy. While following a policy of creating realistic interest of developed countries in Mongolia, it will seek to avoid becoming overly reliant or dependent on any particular country.

4. In formulating Mongolia's foreign policy and determining its priority directions and objectives, a flexible approach shall be applied, paying close attention to the development of international relations and to the regional and world political situation.

5. The priority of Mongolia's foreign policy shall be safeguarding of its security and vital national interests by political and diplomatic means, and creating a favorable external environment for its economic, scientific and technological development.

6. Considerations of foreign relations shall be in the political, economic, scientific, technological, cultural and humanitarian fields of foreign policy.

\section{II.MONGOLIA'S FOREIGN POLICY IN THE POLITICAL FIELD}

7. Mongolia's foreign policy in the political field is an im-portant instrument for ensuring and strengthening its security. Thus its results will be measured first and foremost by how the country's security and independence interests are met, and to what extent its international position has been strengthened and its prestige enhanced.

8. In developing its relations with other countries, Mongolia shall be guided by universally recognized principles and norms of international law as defined in the Charter of the United Nations, including mutual respect for each other's sovereignty, territorial integrity and inviolability of frontiers, right of self-determination, non-interference in internal affairs, non-use of force, settlement of disputes by peaceful means, respect for human rights and freedoms, and equal and mutual beneficial cooperation.

9. In its foreign policy Mongolia shall uphold peace, strive to avoid confrontation with other countries and pursue a multi-based policy. While always championing its national interests, it will at the same time respect the legitimate interests of other countries and its partners. Mongolia will not interfere in the disputes between its two neighboring countries unless the disputes affect Mongolia's national interests. It shall pursue a policy of refraining from joining any military alliance or grouping, allowing the use of its territory or air space against any other country, and the stationing of foreign troops or weapons, including nuclear or any other type of mass destruction weapons on its territory. 
10. Mongolia shall seek to guarantee its interests in the international arena through bilateral and multilateral treaties and agreements, Mongolia shall respect and observe international law, and fulfill in good faith its obligations under international treaties.

11. As a member of the world community, Mongolia shall strive to make active contributions to the common cause of settlingpressing regional and international issues. In doing so, it shall be guided primarily by its national interests, values and fundamental principles.

12. In implementing its foreign policy, Mongolia shall be guided by the following:

a. Maintaining friendly relations with the Russian Federation and the People's Republic of China shall be a priority direction of Mongolia's foreign policy activity. It shall not adopt the line of either country but shall maintain in principle a balanced relationship with both of them and shall promote all-round goodneighborly cooperation. In doing so, the traditional relations as well as the specific nature of our economic cooperation with these two countries will be taken into account.

b. The second direction of Mongolia's foreign policy activity shall be developing friendly relations with highly developed countries of the West and East, such as the United States of America, Japan, and the Federal Republic of Germany. At the same time, it will also pursue a policy aimed at promoting friendly relations with such countries as India, the Republic of Korea, Thailand, Singapore, Turkey, Denmark, the Netherlands, Finland, Austria, Sweden, and Switzerland, and at creating and bringing to an appropriate level their economic and other interests in Mongolia.

c. The third direction of Mongolia's foreign policy activity shall be strengthening its position in Asia and securing a constructure participation in the political and economic integration process in the region. Within the framework of this objective, greater attention shall be given to Asia and the Pacific region, in particular to Northeast and Central Asia. Mongolia shall take an active part in the process of initiating dialogues and negotiations on the issues of strengthening regional security and creating a collective security mechanism. It will strive to become a member of the Asia-Pacific Economic Cooperation forum (APEC). Prerequisites for participating in regional integration shall be created primarily through expanding and promoting bilateral re-lations with the countries of the region.

d. The fourth direction of Mongolia's foreign policy activity shall be promoting cooperation with the United Nations Organization and its specialized 
agencies, and with international financial and economic organizations, including the International Monetary Fund, the World Bank and the Asian Development Bank.

e. The fifth direction of Mongolia's foreign policy activity will be developing friendly relations with the countries of the former socialist community as well as the newly independent states. When developing relations with these countries, a flexible approach will be adopted, reinforcing the positive legacy of our past relations while at the same time taking into account the potential of promoting relations in conformity with new circumstances. Particular attention will be given to promoting relations with Poland, Hungary, and the Czech Republic in Eastern Europe as well as with Kazakhstan, Ukraine, Belarus, Kyrgyzstan and Uzbekistan.

f. The sixth direction of Mongolia's foreign policy activity shall be developing friendly relations with developing countries and cooperating with them, as much as possible, in the solution of common objectives. Beyond the framework of bilateral relations with these countries, this task will be realized mainly through cooperation within the framework of international organizations and movements such as the United Nations, the Group of 77, and the Non-Aligned Movement.

13. The placement of Mongolia's plenipotentiary (diplomatic) representatives abroad shall be carried out with due regard to directions of foreign political relations so as to ensure conditions for their implementation.

14. The assignment of highly qualified and competent personnel from the economic, scientific, and technological spheres to Mongolia's diplomatic missions abroad shall be deemed a matter of principle.

\section{ECONOMIC FOREIGN POLICY}

15. The fundamental objective of Mongolia's policy concerns foreign economic relations lies in the optimal use of external factors to achieve adequate solutions to long-term and current economic goals in the light of the concept of sustainable development and in eventually securing a proper place for its economy in regional economic integration.

16. In developing economic relations and cooperation with foreign countries, Mongolia, while safeguarding against any adverse impact on its economic security and against becoming dependent on any given country, shall pursue a policy designed to ensure conditions leading to equality, mutual benefit and faith- full fulfillment of obligations, freedom from political and other pres-sures, based on the principles and norms of international eco-nomic relations. 
17. in the implementation of projects connected with establishing economic, customs, and. trade special zones, joint ventures or enterprises with full foreign investment or with granting concessions, their political and economic consequences shall be thoroughly examined to ensure that they do not adversely affect the country's economic security and that they will bring economic gains.

18. In selecting partners in the implementation of projects of crucial importance to the national interests, political interests shall have a significant role to play.

19. External debt issues shall be settled without detriment to national economic security, and loans will be accepted on the basis of a thorough assessment of guarantees of their repayment and effective utilization.

20. In developing foreign economic relations, Mongolia shall adhere to the following main guidelines:

a. foreign economic activities shall be focused on enhancing the country's potential, increasing export resources, develop-ing economic infrastructures, and producing import-substituting goods;

b. mindful of the need to modernize the economy, presently dominated by raw materials production, and to develop basic sectors conducive to building a rational structure, measures will be taken to achieve the most effective level of processing minerals as well as raw materials of animal and plant extraction and to produce goods that are competitive on the world market;

c. pursuing the policy of modernizing existing industries by re-equipping them with advanced technology and techniques, and developing export-oriented industries such as food, light, mining and chemical industries, as well as biotechnology and new products on the basis of raw materials available in the country;

d. in enhancing its export potential, Mongolia shall pro-mote cooperation with foreign countries in the fields of process-ing mineral resources, including gold, copper, molybdenum, ura-nium and of manufacturing finished products thereof, as well as in the area of full processing agricultural raw materials and pro- during goods capable of competing on the world market;

e. expanding markets for Mongolia's export items;

f. developing fuel, energy, transportation, communications, and other necessary components of the economic infrastructure and creating favorable conditions for securing access to seaports and transit to them;

g. integrating in the international transportation, information, and communications networks, particularly those in Northeast Asia; 
h. pursuing a policy of securing foreign assistance and technology for developing small and medium industries oriented toward the production of import-substituting goods;

i. taking advantage of Mongolia's natural, historical and cultural heritage, international tourism will be developed by en-hancing its material basis and raising its service level to world standards

j. securing most favored nation treatment in foreign trade and retaining for a certain period of time the status which enables Mongolia to get soft loans and grants.

\section{IY. FOREIGN POLICY IN SCIENCE AND TECHNOLOGY}

21 The main objective of foreign relations in the scientific and technological fields will lie in making full use of external factors to build and enhance a modern national scientific, technical and technological potential capable of serving as a driving force for the effective development of the national economy and industry and able to be competitive at regional, continental and global levels.

22. Mongolia shall apply the principle of benefiting from world scientific and technological achievements to enrich the pool of national endowment and intellectual capacity which are con-groups with the national human and natural resources, the level of social theory and though as well as with the unique culture of its pastoral livestock economy.

23. In implementing its scientific and technological foreign policy, Mongolia shall adhere to the following basic guidelines:

a. introducing advanced technology and methods into production and services. In doing so, priority will be given to the selective introduction of knowledge-intensive technology. Greater attention will be paid to introducing technologies related to processing mineral resources, raw materials of animal and plant extraction, and the use of renewable energy sources;

b. gearing the national scientific and technological information system to the international information network;

c. developing bilateral and. multilateral cooperation in the fields of intellectual property as well as science and technology.

\section{Y. CULTURAL AND HUMANITARIAN POLICY}

24. The main objectives of cultural and humanitarian for-eign relations reside in protecting the culture and way of life of Mongols, endowing their unique cultural heritage, enriching it with the achievements of world culture, restoring national historical and cultural assets, recovering cultural and art rel- 
ics from abroad, using cultural cooperation for the purpose of educating and train-ing skilled personnel capable of working in new conditions, intro-ducing Mongolia to foreign countries, expanding the ranks of well-wishers and supporters of Mongolia, encouraging Mongolian Stud-ies in other nations, and promoting mutual understanding and trust.

25. In promoting cultural and humanitarian cooperation, Mongolia shall practice both Government and people's diplomacy, and apply the principle of respect for human rights, freedoms, equality, and mutual benefit.

26. In developing humanitarian relations with foreign countries, Mongolia shall adhere to the following guidelines

a. safeguarding the rights, freedoms, legitimate interests and security of Mongolian citizens residing or traveling abroad through the promotion of wide cooperation with foreign countries in the legal sphere;

b. enhancing contacts and cooperation with Mongolian nationals residing abroad and mutual support in preserving and developing the Mongolian language, culture, and traditions as well as securing their contributions to Mongolia's progress and growth;

c. taking preventive measures to thwart the influence of reactionary movements and groups prejudicial to the national security of Mongolia and unity of its people;

d. giving priority to the training in developed countries of Mongolian students, managerial personnel and specialists in the fields of market economy, politics, law, management and marketing as well as in the leading areas of the country's scientific and technological fields. In doing so, Mongolia shall seek to benefit from specialized funds of international organizations and developed countries, scholarships of public and private universities and institutes for the purpose of training students, upgrading specialists, arranging degree studies, training highly skilled workers as well as for using the services of foreign lecturers and scholars of excellence;

e. studying the advanced methods and technology of training and management of foreign countries in general education and vocational training with a view to applying them flexibly in a way suitable for the country's specific conditions;

f. in restoring and protecting Mongolia's historical, cultural and natural heritage and assets and in sharing them with other nations, Mongolia shall cooperate with Asian countries which have similar historical, religious and cultural legacies as well as with other interested countries, UNESCO, and other related international organizations; 
g. promoting active relations with international organizations, foundations and non-governmental institutions in the fields of education, culture, arts, sports, and information, according to relevant treaties, establishing and promoting direct ties among similar organizations, encouraging the exchange of scholars, teachers, creative workers, representatives of the media, and sportsmen, taking part in international cultural, art, and sport events, and organizing such measures in the country;

h. promoting cooperation designed to help bring favorable external conditions for ensuring the country's ecological security, maintaining its ecological balance, and protecting nature. 